\title{
ETNOGRAFÍA DE REFUGIADOS CONTEMPORÁNEOS EN LA ARGENTINA
}

\author{
Tamajara Janaina Luiz da Silva ${ }^{1}$
}

\begin{abstract}
Resumen: Este trabajo es resultado de una investigación que se propuso comprender el universo social de los africanos refugiados y solicitantes del estatuto de refugio en la Argentina. Por medio de una estrategia etnográfica se pudo identificar distintos momentos por los que transitan estos actores en dicho proceso. Reconstruir sus narrativas posibilitó, no sólo entender como cada interlocutor argumentó ser reconocido como refugiado, sino también el rol que asumen los actores institucionales en el sentido de hacer replanteos sobre el propio reconocimiento de refugio. El tránsito etnográfico por esos diferentes momentos pretende evidenciar la compleja trama de relaciones, representaciones, actores, instituciones, procedimientos y legislación vigente que se interponen en la vida de los africanos que solicitan refugio en la Argentina.
\end{abstract}

Palabras Clave: Refugiados. Africanos. Argentina. Mediadores y burocracia.

Abstract: This work is the result of an investigation that was to understanding the social world of African refugees and asylum seekers in Argentina. Through an ethnographic strategy could identify the different stages through which pass these actors in the process. Reconstruct their narratives enabled, not only to

1 Investigadora UNaM-CONICET. Licenciada en Ciencias Sociales por la Fundação Universidade Regional de Blumenau-Brasil, Magister en Antropología Social en la Universidad Nacional de San Martín-Argentina. Actualmente es doctoranda en Antropología Social en la Universidad Nacional de Misiones-Argentina por intermedio de la Beca Doctoral del CONICET (Consejo Nacional de Investigaciones Científicas y Técnicas) y está cursando la especialización internacional en la Fundación Henry Dunant- Chile en Derechos Humanos y Políticas Públicas de Protección de Refugiados y Migración. E-mail: tamalogia@gmail.com 
understand how each party claimed refugee status, but also assume the role of institutional actors in the sense of making reconsiderations on granting of asylum seekers. The ethnographic transit through these different times, aims to present the complex web of relationships, representations, actors, institutions, procedures and legislation that stand in the lives of Africans seeking refuge in Argentina.

Keywords: Refugees. Africans. Argentina. Mediators and bureaucracy.

\section{INTRODUCCIÓN}

El trabajo etnográfico ${ }^{2}$ puede posibilitar desactivar una serie de ficciones producidos en torno del "otro". En donde establecer una perspectiva crítica implica la "construcción de parámetros descriptivos" $^{3 "}$. Esta estrategia implica alejarse de los términos corrientes comunes que suelen utilizarse para identificar y delimitar ciertos colectivos sociales. Entre los hechos y las ficciones elaboradas acerca del "otro", por lo general, hay todo una trama de relaciones por ser comprendida. He aquí, que las historias ${ }^{4}$ de los solicitantes del estatuto de refugiado tiene como objetivo hacer conocer y comprender las narrativas, las representaciones, las redes sociales que se interponen en la vida de los interlocutores que se dislocan desde África subsahariana y buscan reconocerse como refugiados en la Argentina.

En el país, según los datos del 2008, había 3.057 personas reconocidas como refugiadas frente a un poco más de 11 mil solicitaciones de refugio desde $1985^{5}$. En lo relativo al género de los solicitantes, hay un promedio de $33 \%$ mujeres y $67 \%$ hombres. El análisis específico de la cantidad de personas provenientes del continente africano revela un total de 1499 trámites iniciados, de las cuales $30 \%$

2 Es un tipo de investigación minuciosa que se basa en la observación y la entrevista etnográfica, abordando la construcción del conocimiento desde la perspectiva del análisis antropológico. Trata de desentrañar estructuras de significación., de interpretar los significados de las acciones, gestos, símbolos a través de la reconstrucción de la perspectiva de los sujetos de estudio sobre un fenómeno social observado. Para ampliar sobre el método etnográfico ver: Guber (2001).

3 Telles y Hirata (2007) señalan que la “construcción de parámetros críticos” implica al mismo tiempo la producción de parámetros descriptivos que permitan poner en perspectivas realidades urbanas en mutación.

4 Se esclarece que se utilizará en el texto las cursivas para evidenciar los términos y expresiones literales empleadas por los interlocutores, reconstruidas a partir de las notas de campo. Las dobles comillas (“") serán utilizadas para los conceptos teóricos y términos sin traducción.

5 Estadísticas del CE.PA.RE (1985-2008): <http://www.acnur.org/index.php?id_pag=3368>. 
fueron reconocidos como refugiados y $53 \%$ denegados. Las nacionalidades africanas con mayor incidencia de reconocidos como refugiados son: senegalesa, argelina, nigeriana, ghanesa, maliense, angoleña, marfileña y congoleña.

De este modo, se puede observar que este fenómeno de los refugiados en termos cuantitativos puedo no ser tan representativo, en especial, los provenientes del continente africano. El interés por estudiar la población africana en Argentina surge justo de su poca visibilidad en el escenario nacional, según el Censo del 2010 en Argentina el $0,37 \%{ }^{6}$ de su populación se autorreconocen como afrodescendiente. Estos dados me generan una serie de interrogantes ligados a la integración local de la población africana en el país. Además, el desconocimiento a respecto de lo que sería un refugiado, conforme relatan estos actores, ayuda a crear muchos imaginarios acerca de los chicos de los paraguas - termo nativo alusivo al suporte adonde se lleva las bisuterías utilizadas para la venta ambulante ${ }^{7}$ que tiene el formato de un paraguas - además de generar interrogantes y comentarios en la calle como: ¿Por qué te pintaste así? ¿Y qué hacen acá?, ¡Mirá se besan la mano! y casi no hay mujeres...

Abdelmalek Sayad (1998), uno de los autores clásicos de los estudios sobre los movimientos migratorios, señala que las "representaciones colectivas" construidas acerca de los migrantes, por lo general, enmarcan el entendimiento que en el principio define y que se va actualizando sobre estos sujetos: o sea, que el hecho de dejar el universo familiar del cual se pertenece "naturalmente" no pasaría de una provocación, pasajera por definición. Estas "percepciones colectivas" provocarían una suerte de ilusión acerca del "estatus provisorio", en tránsito de los migrantes y, por lo cual, se aceptaría en la medida que este pueda traer algún beneficio económico de forma temporaria a la sociedad, es decir, cuando haya trabajo que se tornaría una condición necesaria de su temporalidad que permite ese sujeto estar allí.

En ese sentido, si el trabajo se tornaría una de las premisas básicas de aceptación de este sujeto de manera temporaria en el país que inmigra ¿qué pasa con este sujeto que es un refugiado? Por lo cual, se puede ver afectado tanto la premisa del carácter de temporalidad - debido al principio

6 Según el Censo de 2010 en el interior de una población de más 40 millones de personas, 149.493 personas se autorreconocen como afrodescendientes: 76.064 varones y 73.429 mujeres en territorio argentino. Para ampliar información ver: $<$ http://www.censo2010. indec.gov.ar/index_afro.asp>.

7 La venta ambulante de bisuterías constituye una importante fuente de ingresos para esta población en el país. 
de no devolución al país cuando se le reconoce como refugiado -, cuanto la del trabajo que no sería su principal motivación para migrar. Esta pregunta inicial me llevó a entender la importancia de las historias narradas por los solicitantes de refugio y el rol que las mismas asumen en el contexto estudiado. Lo que evidenció un "universo social" complejo, donde las fronteras de lo que sería un refugiado son difíciles de delimitar, resultado de diferentes interpretaciones de los marcos jurídicos vigentes. Esta es la propuesta de este trabajo, poner a la luz estas divergencias y permitir el debate.

Para ello, busqué reinscribir las narrativas del reconocimiento de refugio a partir de un "proceso de producción", lo que dio lugar a una constante edición de los relatos, reinterpretación de las relaciones, representaciones y de los eventos que eran observados. Alejando de una definición universal de refugiado y conduciendo a percibir los varios sentidos fragmentarios y locales que pueden ser dados a esta categoría. Los aspectos singulares de las trayectorias de solicitantes del estatuto de refugiado permitieron organizar sus relatos a partir de dos momentos claves observados en la trama: el estar en refugio - marcado por las historias de salida y travesía de sus países, bien como, el ser reconocido como refugiado - caracterizado por los relatos de llegada a la Argentina y la solicitud de refugio. Comprender estos dos momentos evidenció diferentes perspectivas sobre la categoría de refugiado en el campo, tanto por parte de los actores que se auto-adscriben como refugiados, las instituciones administrativas que otorgan este estatuto y las organizaciones que brindan auxilio jurídico para los solicitantes de refugio.

El trabajo de campo fue realizado desde meados del año de 2009 hasta 2012 durante mi trabajo como antropóloga en una organización no gubernamental que busca dar visibilidad a este colectivo en Argentina. Al total 12 interlocutores fueron contactados desde la institución con la finalidad de compartir sus historias, entre ellos solicitantes de refugio y refugiados de cinco países: Angola, República Democrática del Congo (ex Zaire), Costa de Marfil, Ghana y Senegal. Las entrevistas fueran

8 Veena Das (1999) señala que los actos de violencia cuando ocurren de forma dramática - como en el caso de la violencia en gran escala producto de una guerra civil - no pueden ser entendidos encerrados en una narrativa única, pero de una forma de texto que es contantemente revisado, en "proceso de producción". Desde diversas fuentes y realizando una investigación multisituada, sostenida por observaciones, entrevistas, análisis de debates públicos y relatos de vida de las víctimas, Veena Das se aleja de una mirada totalizadora y construye una imagen de la nacionalidad india fragmentada y dialógica, que es cuando la unidad va adquiriendo forma de mosaico. 
realizadas en sus viviendas, en espacios institucionales y, en especial, en la calle que representa uno de sus principales espacio de trabajo.

Todavía vale aclarar que fueron creados nombres ficticios para los solicitantes de refugio/refugiados con la intención de preservar la seguridad los mismos. Asimismo, a diferencia con los solicitantes de refugio y refugiados, no establecí nombres ficticios a las organizaciones de la sociedad civil (ONG's), pero hice lo posible para preservar sus nombres, puesto que espero que los espacios de reflexión ${ }^{9}$ sigan representando ámbitos intermitentes de negociación y, por qué no, de rupturas en esta telaraña. No obstante, en relación a los organismos estatales, entendí que la omisión de sus nombres comprometería la comprensión de este trabajo, aunque resguardé la identidad de sus agentes.

\section{EL ESTAR EN SITUACIÓN DE REFUGIO}

La trayectoria emprendida por estos actores para probar su drama, me hicieron identificar dos momentos significativos en sus narrativas: estar en situación de refugio y ser reconocido como refugiado. Lo que creaba otros dos desafíos centrales, en primer lugar, conocer sus historias de salida y travesía pues esta experiencia le posibilita autorreconocer como refugiado al momento de cruzar la frontera y, en segundo lugar, era necesario observar sus relatos de llegada al país y entender qué implicaba "probar" la veracidad de su historia. Percibir este estar/ser un refugiado aparecieron como claves para comprender la experiencia de los refugiados africanos en Buenos Aires.

Cabe aclarar que al pensar este momento de estar/ser, en este texto, no se refiere a una categoría constitutiva pues esta experiencia no les constituyen en refugiados, sino que les reconoce como actores que vivieron una situación singular en un determinado momento y buscan protección de otro Estado. En ese sentido, funciona acá como una categoría analítica que permite entender sus trayectorias y los elementos que posibilitaron o no tal reconocimiento. Asimismo, la experiencia de refugio está ligada a un constante movimiento de "idas" y "vueltas", del "pasado" y "presente", del "emigrar" para "inmigrar" en sus narrativas, donde las fronteras entre estar/ser pueden no ser tan claras. No obstante, en este texto

\footnotetext{
9 Denominé espacios de reflexión a los ámbitos que se propusieron reflexionar sobre la situación de los migrantes y refugiados en la Argentina desde la modalidad de talleres, conferencias o reuniones que aglutinaron diversos actores de organismos estatales, no gubernamentales e investigadores del tema durante el año de 2009-2010 en la CABA.
} 
cumplen con la finalidad de ordenar el trabajo, algunos acontecimientos ligados a sus historias de salidas, travesías y llegadas pueden mezclarse al ser relatadas de forma anacrónica por ejemplo.

El estar en refugio, está relacionado con los relatos singulares, con las historias que narran los solicitantes de este estatuto al momento de su desplazamiento y estos relatos no siempre reconocidos por las leyes de refugio como las circunstancias vividas por Ariel. El salir para Ariel estuvo motivado por problemas familiares, relató con bastante desconfianza que tomó un barco desde Senegal que lo llevó hasta Brasil, llegando en la Provincia de San Pablo en el año de 2008 cuando tenía 18 años de edad. El joven entonces tomó un micro en este mismo año hasta la frontera de Uruguayana (Paso de los Libres) y de ahí vino en un tren carguero hasta Buenos Aires, en su travesía cuenta que siempre viajó sólo y relata que no tenía ningún contacto en la Argentina. La historia de Ariel lo que tiene en común con las demás historias es el hecho de vivir una experiencia en su país de origen que le haga decidir desplazarse y considerar que se encuentra en una situación de refugio. El sentido de agente activo para estos interlocutores, en este trabajo, está relacionado con la toma de conciencia de irse a partir de una experiencia que orientó sus acciones, haber vivido un proceso histórico que lo hizo elaborar un espacio para la acción que le permitió actuar: escapar y solicitar asilo, hace alusión a su decisión.

En algunas narrativas se percibe que la diferencia del tiempo para accionar y tomar conciencia de escapar les posibilita pocas interrogantes de ¿cómo irse? y ¿para dónde irse? Como en el relato de Francisco, en que el estar en situación de refugio es un hecho difícil de recordar porque pone en escena una experiencia trágica. Francisco partió de Costa de Marfil, según sus relatos, en el año de 2006 junto con otros seis polizones de su país en un buque carguero cuando tenía 16 años, cuenta que temía el gobierno militar porque era una situación muy dificil en que había mucha inseguridad. Por eso, decidieron huir como podían, metidos en la zona de la pala del timón del buque. Uno de sus compañeros de viaje terminó muriendo durante la travesía en la región de La Plata al salir del barco para avistar adonde había parado, hecho este todavía está presente en los recuerdos de Francisco. La travesía de los chicos duró 17 días en un barco que relató desconocer el destino, cuando llegaron a La Plata la Dirección Nacional de Migraciones (DNM) fue avisada de la existencia de polizones en el barco carguero que atracó horas después en la municipalidad de San Lorenzo, provincia de Santa $\mathrm{Fe}$ - a 17 km de su capital Rosario.

En las narrativas, como las de Francisco, los mecanismos enunciativos que construyen su experiencia 
en cuanto refugiado al estructurar su relato y enmarcarlo en un colectivo específico: los refugiados, no es algo por lo cual se tomó conciencia a priori y orientó sus acciones para que él se auto-adscribiera como tal, sino fue un hecho que Francisco conoció a partir de que bajó de un barco: se enteró que se encontraba en situación de refugio por otro actor. Es interesante pensar que la desconfianza puesta en escena por él durante la entrevista no parecía ser motivada sólo porque, una vez más, este muchacho estaba adelante de un "otro" contando su historia. Me atrevo a señalar que también tiene que ver con lo que estuvo explícito en sus gestos, su manera de hablar, del enojo y de la desconfianza que tenía del estatuto de refugiado que para él no sirve para nada. Hecho este que puede estar relacionado con la expectativa que construyó acerca de este reconocimiento al enterarse sobre sus derechos por otro actor.

Ya la experiencia de Mariana, es relatada desde su casa ubicada en la provincia de Buenos Aires, ella cuenta que llegó a la Argentina en 1993 cuando tenía 29 años. Licenciada en Administración de Empresas en el Zaire, conforme ella denomina la actual República Democrática del Congo. En Argentina hizo varios cursos de fotografía digital con la ayuda de las instituciones que brindan asistencia a los refugiados y consiguió por intermedio del programa de micro emprendimiento del ACNUR acceder a préstamos para comprar su material del estudio. Nunca imaginó venir a la Argentina, su destino final era Bélgica pero al llegar a Brasil su familia: exmarido, hijo recién nacido y excuñado, fueron robados por un compatriota que les prometió ayuda. Como Brasil también pasaba por una situación económica difícil, le indicaron migrar hacia Argentina con unos pocos dólares que les restaban. Tuvo que huir del Congo, ex Zaire porque cuando estalló la guerra civil ella vivía en provincia por motivos laborales y su familia vivía en capital, al momento del conflicto las personas que estaban localizadas en la provincia no pudieron volver a la capital y viceversa. Decidieron escaparse a Angola en un barco en un viaje de 8 horas donde una familia de amigos los recibió, pero no tardó mucho tiempo para empeorar la guerra civil en este último país. Luego ellos tuvieron que salir de esta ciudad fronteriza en Angola para partir hacia Brasil, que era uno de los pocos países que mantenía la frontera abierta y, de ahí decidieron migrar a la Argentina de colectivo por la ciudad de Foz de Iguaçu.

De este modo, lo que busqué reconstruir en este apartado fueron las trayectorias de desplazamiento: describir una situación que los interlocutores consideran estar en refugio. Estas diferentes maneras de lograr saliry atravesar muestran la particularidad de las historias y sus dinámicas propias. Sin embargo, al escuchar las singulari- 
dades desplegadas en cada relato luego entendí lo dificultoso que podría representar "encuadrarlo" en una normativa jurídica, por ello también era necesario comprender que había sucedido con cada uno de estos interlocutores al llegar al país y solicitar refugio.

\section{LAS TRAYECTORIAS DE LLEGADA}

Para ser reconocido como refugiado no es opcional contar su tragedia, todo lo vivido en la trayectoria de salida y travesia, aunque para muchos representan momentos difíciles de tener que narrar pocas horas o días de su llegada al país, son elementos que testimonian su drama y cabe a la Comisión Nacional de los Refugiados en Argentina (CONA$\mathrm{RE})$ reconocer estas historias como de refugio. De esta manera, al llegar en la Argentina en el año de 2008 Ariel cuenta que le indicaron la CONARE, y que cuando fue a la institución llamaron el Tutor de los niños, niñas y adolescentes no acompañados de la Defensoría de la Nación; ya que Ariel en este momento era menor de edad. Le dieron asistencia legal, una habitación y dinero para comprar lo que necesitaba hasta cumplir 19 años, no obstante, su solicitación del estatuto de refugiado fue denegada; junto a los abogados se intenta cuestionar esta resolución. El interlocutor actualmente vive en habitación de hotel y sobre su relación con las personas en el país dice que hay de todo, personas buenas y malas, la gente que no te trata bien es la que no sabe, la que no te conoce. Su proyecto en la Argentina es terminar la secundaria, vende bisuterías en la calle y su futuro dejo en la mano de Dios, sólo él sabe que va pasar.

Ya en la trayectoria de llegada de Francisco, que arribo en el año de 2006, comprendí que al huir de su país en barco no tenían idea a que país habían llegado al desembarcar en la ciudad de Rosario. Francisco resolvió migrar a Buenos Aires aunque algunos de los chicos que llegaran con él de Costa de Marfil se quedaran en la capital santafesina. Consiguió ser reconocido como refugiado en pocos meses y, una organización de la sociedad civil inicialmente le daba para comer y alquilar; a partir del estatuto de refugiado tramitó su Documento Nacional de Identidad (DNI). Francisco dio énfasis a lo que viene sufriendo en relación al racismo, a la percepción que se tiene de los negros porque para ellos - los blancos - no somos personas. Más allá de las dificultades el interlocutor sigue intentando construir proyectos personales como cantar y tener éxito con su banda. Francisco es vendedor ambulante, sus compañeros de trabajo me relataron que tiene un gran talento musical y están buscando un productor para grabar su CD. El interlocutor contó que el laburo con los paraguas es complicado pues la gente no los entiende. 
Francisco contó que hace poco tiempo que le robaron en la calle - su paraguas $-\mathrm{y}$, por eso, tuvo que cambiarse para el conurbano bonaerense y está viviendo con un amigo que le está ayudando.

Mariana relata, que cuando llegó con su familia en la Argentina era un fin de semana, me narró que se quedaron en la plaza con el bebé y me pedía que imaginara una familia de congoleños en los años 90 en la Argentina, todos se acercaban y querían tocar a su hijo, ver si era "real". Una de las personas que se acercó para hablarles en la plaza - en francés - tenía contactos políticos y consiguió tramitar un lugar para que la familia tuviera donde dormir. En los primeros días gestionó su estatuto de refugiada y, en 6 meses tenía su certificado que así la reconocía, con eso pudo tramitar su DNI y extender el reconocimiento de refugio a su hijo. Me contó, además, que debido a los golpes violentos de su exmarido decidió separarse y se fue a vivir en una casa para madres solteras junto con su hijo, donde conoció una asistente social del ACNUR que se convirtió en una suerte del reemplazo de su hermana a quién extrañaba mucho. A través de esta funcionaria también fue brindada asistencia a su hijo quién no habló hasta cumplir los 3 años. Mariana en el país se casó con un fotógrafo argentino con quien tuvo una hija y, me relató, que varias revistas, radios y programas de televisión me llaman para contar mi tragedia. Actualmente tiene la nacionalidad argentina y, aunque en sus documentos se llama Azalee, - nombre impuesto en el gobierno dictatorial de su país ${ }^{10}-$ sigue reconociéndose como Mariana así como los demás familiares, nombre este que también resolvió designar a su hija.

Reconstruir estos relatos de llegada posibilitó entender como cada interlocutor fue fundamentando su demanda en el país, o mejor, cómo argumentó ser reconocido como refugiado. El ser reconocido incluyó las expectativas de los interlocutores, amplió el sentido de refugiado en este texto, pues transcendió los argumentos de confrontación de las causas de sus partidas y travesías con los de "prueba" o efecto, en la medida que añadió sus esperanzas, estrategias, percepciones al reconstruir este momento. Todos estos elementos, representan la "forma" como organizaron su petición y que sustentó o no este reconocimiento.

10 Durante la dictadura Mobutu Sese Seko entre 1971 a 1997, además de cambiar el nombre del país de República Democrática del Congo para Zaire y de algunas ciudades, también ordenó que todos sus ciudadanos adoptasen nombres de origen africano, aún los adultos como Mariana. Para Kabunda (2003) esta decisión, bien como la "zairización de la economía" de Mobutu, podría ser caracterizada por un "falso nacionalismo", ya que su golpe de Estado fue apoyado por la pequeña élite local proccidental. 


\section{EL RECONOCIMIENTO DE REFUGIO Y LAS PRÁCTICAS DE OBJECIÓN}

$\mathrm{Al}$ reconstruir las historias de refugio comencé a entender el rol que asumen los otros actores institucionales, tanto para reconocer, denegar y hacer replanteos sobre el estatuto de refugiado. En este campo los agentes de instituciones gubernamentales (la Dirección Nacional de Migraciones, la Defensoría Pública de la Nación) y las No Gubernamentales (ONG's) y dentro de éstas las Clínicas Jurídicas forman parte del mundo social en el cuál transitan los interlocutores que solicitan refugio. Poner a la luz los procedimientos puestos en práctica por los mismos implicados ayudaba a evidenciar la complejidad del tema, los desafíos y los compromisos, encarnados por los agentes institucionales que trabajan a diario con este colectivo. Permitiendo comprender, en especial, los aspectos jurídicos del reconocimiento del estatus de refugiado, y qué implicaba su denegación.

A partir de este entendimiento logré reflexionar sobre la diferencia que se interpone entre la ley y su práctica, un aspecto que resulta central. Estos elementos también posibilitaron entender desde otro punto de vista el itinerario que tienen que hacer los solicitantes de refugio. En ese sentido, más allá de lo que escuchaba en las entrevistas al nombraren algunas instituciones por las que habían pasado al llegar a la Argentina era necesario elucidar y entender este otro universo de significación: el conformado por los actores institucionales.

E1 reconocimiento del estatuto de refugiado es un procedimiento administrativo otorgado por la CONARE ${ }^{11}$, institución gubernamental interministerial que funciona en el ámbito de la Dirección Nacional de Migraciones (DNM) y que depende a nivel organizacional del Ministerio del Interior. El marco legal utilizado es la Convención sobre el Estatuto de los Refugiados del 28 de julio de 1951 que establece los principios sobre los cuales se construye el régimen de la protección internacional para los refugiados. Esta misma Convención fue fortalecida por el Protocolo de 1967 que incluyó una gama más amplia de situaciones de refugio. A su vez, para el ámbito americano en el año de 1984 se adoptó la Declaración de Cartagena que amplió el establecido por la Convención de 1951 y el Protocolo de 1967, según este instrumento serán considerados refugiados "las personas que han huido de sus países porque su vida, seguridad o libertad han sido amenazadas por la violencia generalizada, la agresión extranjera, los conflicto internos, la violación masiva de los derechos humanos

11 Hasta la conformación de la CONARE, el órgano de determinación de la condición de refugiado era el Comité de Elegibilidad para Refugiados (CEPARE) creado en el año 1985. 
u otras circunstancias que hayan perturbado gravemente el orden público" (DECLARACIÓN DE CARTAGENA SOBRE REFUGIADOS, 1984, SECCIÓN III). En Argentina, en diciembre de 2006 el Congreso de la Nación sancionó la Ley General de Reconocimiento y Protección al Refugiado $\mathrm{N}^{\circ} 26.165$ que incorporó al derecho interno los instrumentos internacionales citados anteriormente.

Para solicitar el estatuto de refugiado se debe presentar una carta a la CONARE detallando las razones por la que salió de su país y toda documentación que ayude a probar su identidad e historia - sino lo tienen, deben explicar el motivo. El solicitante es citado para una entrevista personal a fin de que narre en detalle todo lo vivido. Las autoridades entregan al solicitante un certificado de residencia provisorio - la precaria como suele ser llamada - que acredita su permanencia regular en el país mientras se analiza su historia.

Al resultar favorable decisión de solicitud, es decir, si se le reconoce la condición de refugiado, se le entrega un certificado para que él mismo pueda tramitar su residencia temporaria en el país - por dos años - que es prorrogable y es lo que le permite tramitar el DNI (Documento Nacional de Identificación). Un importante esclarecimiento señalado por el agente de la Defensoría de la Nación es que el Estado reconoce el estatuto de refugiado de una persona, no es constitutivo, es una decisión declarativa del
Estado Argentino que reconoce una situación de hecho dada, si vos saliste de tu país porque de perseguían por tu color de piel o por tu opinión política, lo que el Estado hace es reconocer este estado de poseer. Pero si no se le reconoce el estatuto de refugiado, una de las opciones es la de tramitar la residencia ante la DNM, no como un refugiado sino como un migrante por razones humanitarias, de trabajo o estudio. Justamente aquí es cuando el tema se torna más complejo, porque los papeles de carácter obligatorio que se solicita para ser un migrante son distintos de los exigidos para ser reconocido como un refugiado.

La otra opción es apelar a la decisión de la CONARE ante el Ministro del Interior y se esta decisión también resultara negativa, los solicitantes pueden emprender una larga causa jurídica que puede llegar hasta la corte suprema por intermedio de abogados de organizaciones no gubernamentales que poseen Clínicas Jurídicas y/o a través de abogados de la Defensoría General de la Nación cuestionando esta denegación. Sobre la "forma" de apelar de una denegación de la CONARE, de acuerdo con el relato del agente de la Defensoría, la definición de que lo sería un verdadero refugiado en la Declaración de Cartagena basado en el temor fundado por persecución y, que sirve de base para el reconocimiento de estatuto de refugio, también permite otras interpretaciones. De esta 
manera, desde otras interpretaciones posibles los abogados que actúan acá como mediadores sostienen sus apelaciones: se puede interpretar de todo en la Declaración de Cartagena ¿qué es persecución?, ¿qué es opinión política?, ¿qué es religión?, ¿qué es temor?, ¿qué es temor fundado?, ¿cuándo hay un temor fundado?, ¿cuándo no? a la luz de una situación objetiva del pais de origen, todo eso es materia para apelación, señala. En el caso de los NNA también hay una discusión específica que reconoce formas determinadas de persecución dirigidas a los niños, entre estás la negación a Derechos Económicos y Sociales. Por ello, si un niño que integra un grupo familiar determinado, como los niños en situación de calle, no logran satisfacer sus Derechos Sociales y Culturales a un nivel de umbral mínimo - lo que por sí sólo ya permite una larga discusión en relación a su delimitación - puede ser entendido, por ejemplo, como persecución por su condición social y, por lo tanto, se podría defender su reconocimiento como refugiado en base a estas otras interpretaciones. De igual manera, los que en la actualidad son denominados refugiados ecológicos - aunque todavía no son reconocidos como tales por las normativas - pueden forzar a nuevas interpretaciones sobre la definición de refugio.

Por ello, señalo que el tipo de poder que tiene la CONARE no reside en la posibilitad de tener un "saber" del que no se puede objetar, sino más bien, debido a sus "prácticas"; porque cada historia de refugio puede ser interpretada por los agentes de esta última institución en base a la subjetividad de las leyes de refugio, en donde la circulación de la "forma" por la cual se decidió sobre ese reconocimiento es exclusivo y de la misma. Lo interesante en este campo, es que algunos de los actores que buscan reinterpretar las fronteras de lo que sería un refugiado en los procesos de apelación de una denegación también lucharon, desde los años 90, por una reestructuración del campo jurídico en el país a partir del trabajo de las Clínicas Jurídicas. Denunciando sobre las prácticas arbitrarias relacionadas al marco normativo para el tema de migración instituido en la última dictadura militar argentina: la ley Videla ${ }^{12}$.

La derogación de esta última ley, en el año de 2004, fue recibida con gran entusiasmo por las organizaciones de la sociedad civil ligadas al tema de migración y derechos humanos debido al fuerte contenido de cláusulas que "afectaban derechos y garantías constitu-

12 Del año de 1981, la Ley 22.439 se tornó conocida como Ley Videla, por hacer alusión al jefe de la junta militar que gobernaba la Argentina en este contexto. 
cionales" como detener personas, expulsarlas sin cualquier tipo de control legal o judicial sobre la decisión ${ }^{13}$. Aquí, surgen alianzas entre distintas organizaciones de migrantes y refugiados como las eclesiásticas, religiosas, sindicales, entre otras - que culmina con un primer diagnóstico acerca de la principal responsabilidad material de violación de los Derechos Humanos resultada de la Ley Videla. Este conjunto de actores, que se nucleaban para advertir sobre la violación de los derechos humanos resignado por los migrantes en la Argentina decidieron definir, no sólo estrategias discursivas, pero también prácticas que posibilitó incidir en una nueva Ley de Migración en el año de 2004 que busca garantizar el "derecho de migrar" y, más adelante, ayudó a producir la primera ley nacional de Refugio del año de 2006.

En ese sentido, el marco normativo citado anteriormente no se limita en buscar ser el regulador de un procedimiento administrativo, sino que además refuerza a entender lo que señala Bourdieu cuando evidencia que "la concentración del capital jurídico es un aspecto absolutamente crucial de un proceso más amplio de con- centración del capital simbólico, bajo sus diferentes formas que constituye la base de la autoridad específica del detentador del poder estatal" (BOURDIEU, 1997, p. 111). Asimismo, fueron etas reflexiones que posibilitaron comprender la configuración social de este campo, bien como, la manera que los instrumentos jurídicos fueron transformándose al largo del tiempo, culminando con la actual forma mundial y regional de reconocimiento del estatuto de refugiado. En este caso específico, analizar cada dimensión de este procedimiento permite analizar las herramientas de poder que se nutren los agentes institucionales para decidir acerca de las "pruebas" que titulan la veracidad de las historias y, entender la manera en que estos mismos instrumentos son utilizados para establecer espacios de rupturas y negociaciones. Esto sucede porque, conforme señala Miranda (2005), la organización burocrática en las instituciones públicas poco se parece con la burocracia racional evidenciada por Max Weber, aquella en que habría una separación total entre la propiedad de los medios de administración y de la propiedad personal del funcionario ${ }^{14}$. El papel de la antropología en ese sentido,

13 Para más detalles ver: Ceriani y Morales (2011).

14 Miranda (2005, p. 3) resume en cuatro las características "típico ideal" de la burocracia descripta por Weber (1979), la primera sería la competencia (sería el ingreso en la organización por intermedio de competencia y la ascensión a través del mérito, la segunda se refiere a la impersonalidad (apego a los instrumentos legales), en tercero estaría la jerarquía (competencias definidas dentro de la división del trabajo y en cuarto la continuidad (en la ocupación del cargo burocrático como profesión). 
haya el desafío de pensar cómo la organización burocrática se estructura en cada sociedad, poniendo en cuestión la idea de un: modos operandi único, racionalizado llevado a cabo por sus agentes.

\section{A MODO DE CIERRE}

Al largo de este trabajo me propuse comprender el universo social de los africanos que solicitantes del estatuto de refugio residentes en Buenos Aires. Por intermedio de una estrategia etnográfica se pudo identificar diferentes momentos, a través del cual, estos actores transitan en dicho proceso. El primer momento, está caracterizado por lograr salir y atravesar un territorio fronterizo, proceso construido de forma dinámica, cuyas narrativas producidas por los solicitantes del estatuto de refugiado son definidas por la singularidad del momento en que consideraran estar en situación de refugio. En el segundo instante, busqué comprender como cada interlocutor argumentó ser reconocido como refugiado, las relaciones que fueron estableciendo en el país y las exceptivas construidas.

Denominado de, tercer momento, es cuando me acerco al mundo de las clasificaciones, de los procedimientos, de las rutinas administrativas y las estrategias políticas. Es allí que, el ser reconocido como refugiado exige del solicitante contactar al universo social caracterizado por actores que $a$ priori "encarnan" instituciones, cuya veracidad de sus historias, no sólo son puestas a "prueba", pero sus evidencias también pueden ser negociadas. Se ha podido comprender que los actores institucionales no operan de modo homogéneo, las diferencias consisten en la interpretación de las "formas" de otorgar este reconocimiento; dado que los mecanismos de apelación también exponen sobre la multiplicidad de interpretaciones posibles y, que pueden entrar en tensión resultado de divergentes percepciones de los marcos jurídicos implicados.

El transito etnográfico por esos tres momentos, pretendió presentar y comprender la compleja trama de relaciones, actores, instituciones, procedimientos y legislación vigente que se interponen en la vida de los africanos que solicitan el status de refugiado. Ahora bien, todas estas discusiones me guiaron a reflexionar sobre los diferentes sentidos construidos por los individuos a partir de las categorías que deben ser "encuadrados" desde el aparato burocrático estatal. A pesar de ser una categoría jurídica creada por el sistema de normativas internacionales, por un lado, se producen acciones sociales locales, "formas de concebir lo social" (O’DOWYER, 2002), lazos de organización a partir de la interacción con actores institucionales $\mathrm{y}$, aunque estos elementos no operan de una manera clara, ellos marcan límites desde sus trayectorias de vida y, la adscripción por "otros" al reconocer su relato bajo este estatuto. 
Todos estos elementos que se fueron desplegando me alejaron de percibir esta categoría como estática. Este "universo social" tan diverso que conformaban las historias, los procedimientos, las representaciones, la diversidad de actores implicados en cada narrativa de solicitud de refugio evidencian lo dificultoso que representa "encuadrarlo" en una normativa jurídica y la frontera entre lo que sería un refugiado completa de delimitar. Lo interesante aquí es que, si bien en los dispositivos legales existe un refugiado "tipo ideal": el que huye de una persecución fundada - lo cual por sí sólo permite varias reinterpretaciones jurídicas -, en la práctica hay pocos elementos comunes que los caractericen como colectivo, ya que cada historia es producto de una experiencia singular.

En ese sentido, pude observar durante este proceso que los actores de las institucionales gubernamentales y de la sociedad civil operan de forma tan heterogénea como las historias de refugio narradas por los interlocutores. Desde la subjetividad de sus prácticas cotidianas formalizadas en el reconocimiento y, en la objeción de la denegación de refugio que se puede negociar esta categoría política. Entiendo a los refugiados desde una categoría política porque este status: "fortalece la lucha por los derechos" ciudadanos, y provoca "reorganizaciones institucionales", crea "la necesidad de la producción de un aparato específico del Estado", de organismos, leyes propias.
Estos acontecimientos instituyen "cambios en los modos de vida y consciencia de aquellos que están involucrados en este proceso" (MEDEIROS, 1998). Las posibilidades de negociación de esta condición, las relaciones de poder que se establecen en son definidas en la consolidación o en la lucha por la ampliación de sus derechos de ciudadanía como en la derogación de la Ley Videla.

Todas estas características complejas de la categoría de refugio podrían ser pensadas desde el concepto de "anomalías" descriptas por Douglas (1973) o a partir de la "liminaridad" pensadas desde Van Gennep (1960) y Turner (1969); categorías estas que ya fueron utilizadas para comprender este status confuso, ambiguo, contradictorio que se encuentran no sólo los refugiados como los migrantes. Entretanto, lo que me apartó de entenderlos a partir de la "posición intersticial" es que esta noción puede llevar a comprenderlos desde un proceso que busqué distanciarme: la idea de que estos interlocutores pueden ser "sujetos en tránsito", resaltando el carácter provisorio no apenas territorial, sino que además social en que muchos veces son percibidos dentro de la sociedad que migran. Al revés, los relatos justamente ponen a la luz las relaciones sociales establecidas en este nuevo lugar, por ello decidí apartarme de la liminaridad y buscar en los espacios que suele ser negociada la categoría de refugio, las respuestas para mis inquietudes. 
La relación entre lo global, y local, el pasado y presente, en estas llamadas "idas y vueltas" que acá no significa un "betwixt and between", fueron leídas a partir de la caracterización que hace Otávio Velho en 1979 de "frontera en movimiento" en los estudios agrarios en Brasil. El autor señala que es a partir las trayectorias sociales de los individuos, clases y los límites impuestos por los mismos es que se pueden interpretar los efectos de la frontera sobre una sociedad, pues estos pueden variar en el tiempo y debido a los usos establecidos por cada grupo. De esta manera, la frontera no representa una línea, límite o avance, son fronteras múltiples y complejas. Esta relación, parece explicitar la posición social que estos actores ocupan en la sociedad en que migran, no apenas porque esta categoría varia localmente, más también los sujetos observados pueden vivir una

\section{REFERENCIAS}

ALLEN, K. El refugio y la migración africana en Buenos Aires. Tesis (Master Internacional en Migraciones). Universidad de Valencia, 2011. BOIVIN, M; ROSATO, A.; Y RIBAS, V. (2004) Constructores de Otre$\mathrm{dad}$. Una introducción a la antropología social y cultural. Eudeba: Buenos Aires, 2014.

BOURDIEU, P. Razones prácticas: Sobre la teoría de la acción. Anagrama: Barcelona, 1997. relación diferente con la misma al curso del tiempo, dependiendo de la relación que van estableciendo en país. Estas analogías pueden ser permanentemente reconstruidas, no son establecidas desde una forma continua dónde en todos los periodos estos sujetos se perciben como "ciudadanos liminares".

Estos fueron los múltiples sentidos locales de la categoría de refugio que busqué transcribir a través de los relatos de los interlocutores investigado. Una categoría dinámica y compleja construida con el propósito de la protección internacional de los individuos que se ajusta a la subjetividad de la interpretación de los sujetos que se auto-adscriben como refugiados, de los que toman las decisiones relativas al reconocimiento y la negociación de este estatuto, a partir de la realidad política de cada país.

CERIANI C., MORALES, D. Avances y asignaturas pendientes en la consolidación de una política migratoria basada en los Derechos Humanos. FIDH - Federación Internacional de Derechos Humanos y CELS-Centro de Estudios Legales, Buenos Aires, n. 559e, feb. 2011. CONARE. Guía de Información sobre la solicitud del estatuto de refugiado en la República Argentina. Disponível em $:<$ www.migraciones. 
gov.ar/conare/pdf/guia_junio_2009. $\operatorname{pdf}>$.

CRISP, J. Una diferencia Vital. A los gobiernos les resulta cada vez más difícil distinguir entre refugiados e inmigrantes. Refugiados, UNHCR/ ACNUR: Geneva, n. 136, 2007.

KABUNDA, M. Dimensión política y cultural de la conflictividad en la República Democrática del Congo. Nova África,. n 13, p. 7-26, 2003.

KOBELINSKI. La evaluación moral cotidiana de los candidatos al estatuto de refugiado en Francia. Runa, n. 28, p. 59-75, 2008.

MAFFIA, M. Una contribución al estudio de la nueva inmigración subsahariana en la Argentina. Cuadernos de Antropología Social, n. 31, p. 7-32, 2010.

MALKKI, L. Purity and Exile: Violence, Memory, and National Cosmology among Hutu Refugees in Tanzania. University of Chicago Press: Chicago, 2005a.

MEDEIROS, L; LEITE, S. Os impactos regionais dos assentamentos rurais: dimensões econômicas, políticas e sociais. Renião da ANPOCS GT1421, Caxambu, 1998.

MIRANDA, A. P. M. Antropologia, Estado Moderno e Poder: perspectivas e desafios de um campo em construção. Revista Avá, Posadas, n. 7, p. 1-27, 2005.
O'DWYER, E.C. Quilombos: identidade étnica e territorialidade. FGV: Rio de Janeiro, 2002. p. 13-42.

PEIRANO, M. A favor da etnografia. Rio de Janeiro: Relume-Dumará, 2005. SAYAD, A. A Imigração ou os Paradoxos da Alteridade. Edusp: São Paulo, 2008.

SIGAUD, L. Armadilhas da honra e do perdão: usos sociais do direito na mata pernambucana. Mana, v. $10 \mathrm{n}$. 1, p. 131-163, 2004.

TELLES, V. D. S.; HIRATA, D. V. Cidade e práticas urbanas: nas fronteiras incertas entre o ilegal, o informal e o ilícito. Estudos Avançados, São Paulo, v. 21 n. 61, p. 173-191, 2007.

TURNER, V. Liminality and communitas. In: The ritual process. Structure and anti-structure. Aldine Publishing Company: Chicago, 1969.

VAN GANNEP, A. The rites of passage. University of Chicago Press: Chicago, 1960.

VEENA, DAS. Fronteiras, violência e o trabalho do tempo: alguns temas wittgensteinianos. Revista brasileira de ciências sociais, São Paulo, v. 14, n. 40, p. 31-42, 1999.

VELHO, O. Capitalismo autoritário e campesinato: um estudo comparativo a partir da fronteira em movimento, v. 45, Difel: São Paulo, 1979. 